\title{
Tetraplegia Resulting from a Bus Roll Over Accident: Case Report
}

\author{
V. B. Hill, MBBS, BPhty, W. E. Davies, AM, FRACP, FACRM, \\ S. Urquhart, MBBS \\ Spinal Injuries Unit, Princess Alexandra Hospital, Ipswich Road, Wooloongabba, \\ Queensland, Australia.
}

\begin{abstract}
Summary
This is a report on a patient injured when an interstate bus overturned. The mechanism of injury is detailed and the secondary factors that resulted in the injury are discussed. Ways in which similar injuries could be prevented are put forward. An urgent plea is made for a more rational approach to the use of restraint mechanisms for bus passengers.
\end{abstract} Key words: Bus accidents; Roll over; Passenger safety cage; Seat belts.

\section{Case report}

A 41-year-old male passenger was in the right hand aisle seat of an interstate bus, four rows from the front. The vehicle left the road while negotiating a right hand curve, skidding 60 metres on its left side, before tilting on to the left side of the roof for another 15 metres and finally falling back on to its left side. The passengers were thrown on to the seats of the left hand side of the bus and when the vehicle rolled up on to its roof, many were then thrown clear of their seats against the luggage rack. The patient was one of those who took the brunt of the impact on to his left shoulder and his head as he struck the luggage compartment. He sustained a Colles' fracture of the left wrist, a comminuted fracture of the left shoulder, a fracture dislocation of $\mathrm{C} 6$ on $\mathrm{C} 7$, pulmonary contusion and complete tetraplegia below C6. There was no evidence of any scratch or abrasion on his body.

\section{Discussion}

The question of seat belts for bus passengers has been discussed ever since seat belts were introduced into cars, but numerous arguments against them have been put forward.

1. Bus accidents resulting in death or serious injury are relatively rare (fatality rate 3.9 per 100 million vehicle kilometres and 35 casualty crashes per 100 million vehicle kilometres) (Bamford, 1987).

2. The cost effectiveness of installing seat belt demands that no more than $\$ 90$ per seat can be justified, if bus travel is to remain economically competitive (Federal Office of Road Safety, 1986; Milne, 1974). 
3. Bus seat are not designed to take the force that they would be subjected to if a seat belt were attached to the frame (Hoffman, 1987; Wojcik and Sanders, 1972).

4. It is thought best to encapsulate a passenger in a well padded seat, which will deform in a controlled way when a passenger is thrown against it in a violent deceleration accident (Federal Office of Road Safety, 1986).

5. Lap seat belts would result in passengers hitting their heads on the back of the seat in front (Federal Office of Road Safety, 1986).

6. Vandalism and a low percentage of utilisation would make the installation impracticable (Federal Office of Road Safety, 1986).

In the case of the accident described above, seat belts would have held passengers in their seats. There was no violent deceleration hence they would not have been thrown against the back of the seats in front. All injuries were the result of passengers being thrown against the left side and the roof of the bus. Fortunately, this was a relatively low velocity injury. Had the bus slid sideways into a tree and stopped in half the distance, many more head and neck injuries could have resulted.

Passengers were fortunate as the bus was of modern European design, and incorporated many of the features currently under review by The Senate Committee on Bus Safety (Federal Office of Road Safety, 1986). The seating was well padded, and designed to resist deformation in a roll over accident. (The roof came down approximately $20 \mathrm{~cm}$ on the left side of the bus and was still well clear of the top of the seats.)

The driver and the front seat passengers wore seat belts, and remained secure and unharmed in their seats.

Every day, many thousands of Australians travel on buses. Safety requirements, passenger numbers, seating requirements and the design and maintenance standards of our buses are well below the standards set in Europe and the USA (Hoffman, 1987). The main categories of bus travellers are:

1. Interstate travellers.

2. Commuters.

3. School children.

Interstate buses travel at high speeds (maximum $100 \mathrm{~km}$ per hour) and are subject to all of the hazards that road users are submitted to. These include sections of poorly engineered road, poorly signed roads, poorly fenced roads in some country areas and other road users who statistically are more accident prone than drivers in almost any other country in the world.

Inevitably, accidents occur and in many cases, the structure of the vehicle is quite inadequate to stand up to 'roll over'. Stylists and an apparent public demand for all round visibility have resulted in extensive use of glass, tubular steel, and plastic in the upper body structures of modern buses. There are no standards set for seat design or roof strength in Australian buses (Dickson et al., 1981).

Commuters require a rapid 'pick up' and 'set down' service with minimum delays, hence buses accelerate and brake suddenly. There is provision for standing passengers. The incidence of severe accidents is statistically low in Metropolitan areas and the majority of casualties results from drivers having to stop suddenly. 
Primary school children in Brisbane may sit three to every two adult seats (School Bus Services and Charter, 1987). Children may stand, but no more than $50 \%$ of the adult seating capacity are allowed to stand while the bus is travelling. A maximum load of 90 children is permitted and if the distance is greater than 32 kilometres, no passenger may stand.

\section{Conclusions}

It is important to ensure that high speed interstate and charter buses have an adequate roof strength to withstand a roll over accident. Front seat passengers and the driver should have seat belts, and seating design should be adequate to allow belts for all passengers if possible. Most people would feel much more at ease in a seat belt since they have already been conditioned to wearing belts in cars and aircraft. Yet another solution would be to have passenger seats facing backwards and in this situation, seat belts could be safely worn.

Commuter buses are relatively safe, but should have seat belts for those passengers who wish to wear them. The chance of injury is far greater in the event of an accident if a passenger is standing, hence it would seem highly desirable that all passengers were seated before the bus moves off.

The safety of school children should be of major concern for all parents. All children should be seated and wear seat belts. The opportunity to ensure that the next generation is conditioned to wearing seat belts is being lost.

\section{References}

BAMFORD J 1987 Australian vehicle design regulations and crash worthiness. Proceedings of seminar on structural crash worthiness and property damage accidents. Murray NW, Grzebieta RH (eds) Monash University Department of Civil Engineering pp 134-144.

Dickson AH, Williams JF, JoUbERT PN 1981 Safety requirements of bus seats and seat anchorage. Department Transport, Australia CR 25.

Federal Office of Road Safety, Evidence to the House of Representatives Standing Committee on Transport Safety 1986 Enquiry into passenger coach safety.

Hoffman E 1987 Surviving the bus crash. Proceedings of seminar on bus and heavy vehicle safety: conducted by the Road Trauma Committee, Royal Australian College of Surgeons in conjunction with the Road Traffic Authority, Melbourne.

MILNE P 1974 The case for providing seat belts in trucks and buses. Document SD 74/92. Prepared for ACSVD (a).

School bus services and charter. Department of Transport information (Queensland) 1987 6/TPT.

WOJCIK CK, SANDERS LR 1972 School bus seat restraint and anchorage systems. UCLA Institute of Transportation and Traffic Engineering. Report to DOT/HS-800 740 PB pp 212-732. 